\title{
Should we be giving high concentration oxygen to all patients treated in an ambulance?
}

\author{
${ }^{1}$ GG Lavery, ${ }^{2} \mathrm{PA}$ Corris \\ ${ }^{1}$ Critical Care Consultant, Belfast Health and Social Care Trust and Clinical Director, Health and Social Care Safety Forum, Public Health \\ Agency, Northern Ireland; ${ }^{2}$ rofessor of Thoracic Medicine, Institute of Cellular Medicine, Newcastle University, Newcastle upon Tyne \\ Hospitals Foundation Trust, Newcastle upon Tyne, UK
}

\begin{abstract}
Oxygen is one of the most widely used drugs. It is important to recognise that oxygen administration carries risks as well as benefits. While adequate oxygen saturation of arterial blood is an important factor in tissue oxygen delivery, oxygen administration to patients with chronic obstructive pulmonary disease can lead to decompensated type II respiratory failure. In this debate, Dr Lavery makes the case that high concentration oxygen should be given to all patients treated in an ambulance, while Professor Corris argues against this position.
\end{abstract}

KEYWORDS Oxygen, emergency care, chronic obstructive pulmonary disease, respiratory failure

DECLARATION OF INTERESTS No conflicts of interest declared.

\author{
Correspondence to GG Lavery, \\ Public Health Agency, \\ 18 Ormeau Avenue, \\ Belfast BT2 8HS, \\ Northern Ireland
}

tel. +44 (0)28903I 1611

e-mail gavin.lavery@hscni.net

Correspondence to PA Corris, Institute of Cellular Medicine,

Newcastle University, Newcastle upon Tyne NE7 7DN, UK

e-mail paul.corris@ncl.ac.uk

\section{High concentration oxygen should be given to all patients treated in an ambulance}

GG Lavery

\section{INTRODUCTION}

The effects of cellular hypoxia include loss of function, cell death and, if widespread within a tissue, infarction and necrosis. Prolonged systemic tissue hypoxia is a frequent precursor to multiple organ dysfunction and death. ${ }^{1.2}$ Adequate oxygen saturation of arterial blood is an important factor in tissue oxygen delivery. Despite the above, there are still questions regarding the use of high concentration oxygen ( $\mathrm{HCO})$ as a (short-term) first-line treatment for patients travelling by ambulance from the scene of illness or injury.

The origin of this uncertainty is a long-running concern regarding the potential harm caused by oxygen therapy, mainly in patients with chronic obstructive pulmonary disease (COPD) ${ }^{3.4} \mathrm{~A}$ recent randomised controlled trial by Austin et al. ${ }^{5}$ recommending the routine titration of oxygen treatment in patients with COPD in the prehospital setting has re-ignited the issue.

\section{THE BENEFITS AND RISKS WITH HIGH CONCENTRATION OXYGEN}

It is more than half a century since $\mathrm{HCO}$ was found to be potentially harmful in some patients with COPD. ${ }^{6}$ In 1980, Aubier et al. ${ }^{7}$ found that COPD patients breathing
$100 \% \mathrm{O}_{2}$ showed an initial fall in minute ventilation which recovered to approximately normal values after 15 minutes. The small increase in partial pressure of $\mathrm{CO}_{2}$ $\left(\mathrm{pCO}_{2}\right)$ observed was primarily attributed to ventilation/ perfusion (V/Q) mismatch. Decreased minute ventilation ${ }^{8}$ and increased deadspace? have also been suggested as factors behind $\mathrm{HCO}$-induced hypercapnia. Nevertheless, it is still common, in both pre-hospital and hospital practice, for COPD patients to receive $\mathrm{HCO} .{ }^{10-13}$ Conversely, many patients with other life-threatening conditions receive too little oxygen. ${ }^{13}$

Oxygen therapy resulting in an excess of oxygen (hyperoxia) may cause significant adverse cardiovascular effects with increased systemic vascular resistance and blood pressure, decreased cardiac output and tissue perfusion. ${ }^{14}$ There is also the potential for increased generation of reactive oxygen species which can damage cells. Early studies suggested periods of hyperoxia lasting days rather than minutes might be detrimental. ${ }^{14-16}$ Under normobaric conditions, it requires a patient to breath $95 \%$ oxygen for 4-22 hours to produce the earliest manifestation of pulmonary toxicity. ${ }^{17}$ More recently, relative hyperoxia has been suggested as having beneficial effects in ischaemic myocardium, oedematous brain and in processes such as the inflammatory response in healing and tissue repair. ${ }^{17}$ 


\section{THE KEY ISSUES}

Should we limit the use of $\mathrm{HCO}$ in the pre-hospital setting in order to protect some patients from potential harm while preventing a large number of patients from receiving benefit? We believe that the dilemma can be solved by appropriate application and monitoring of the treatment.

Austin et al. found a $78 \%$ reduction in mortality associated with the avoidance of $\mathrm{HCO}$ in COPD patients. ${ }^{5}$ However, there were oxygen therapy protocol violations in $37 \%$ of the 214 patients included in the analysis and only $11 \%$ of patients had a blood gas drawn within 30 minutes of arrival in the emergency department as specified by the protocol. In addition, all deaths recorded were attributable to respiratory failure and $70 \%$ occurred within five days of hospital admission. This suggests the influence of other factors such as a less aggressive use of invasive or noninvasive ventilation. The latter had previously been shown to decrease mortality associated with acute exacerbations of COPD. ${ }^{12}$ However, the decision regarding the prehospital use of $\mathrm{HCO}$ should not be based on the perceived limitations of a single study.

\section{OXYGEN AS A DRUG}

Oxygen is a drug and we should consider the indications, contraindications and any special precautions needed when administering $\mathrm{HCO} .{ }^{17}$ We are proposing a strategy which would potentially be applied to all patients in ambulances and so must ensure our deliberations encompass the relative risk of using or withholding $\mathrm{HCO}$, the principle of 'most good for most individuals', the limitations of guidelines and protocols in current clinical practice, and the concept of building reliability in clinical processes.

Tissue hypoxia may be prevented or reversed by increasing poor arterial saturation using $\mathrm{HCO}$, manipulating cardiac preload, contractility or afterload or improving oxygen-carrying capacity. However, monitored fluid loading, infusion of inotropes and use of other vasoactive drugs are interventions not easily achieved as part of pre-hospital care. Increasing oxygen carrying capacity by transfusing blood is relatively ineffective for hours or days due to the low levels of 2,3-diphosphoglycerate in stored red cells (this substance controls the movement of oxygen from red blood cells to body tissues). Thus, augmenting the immediate supply of oxygen is the only rapid, simple and effective method of increasing tissue oxygenation in a pre-hospital setting.

\section{THE TARGET POPULATION - PATIENTS IN AN AMBULANCE}

British Thoracic Society (BTS) guidelines state that patients suffering from major trauma, sepsis, shock, asthma, pneumonia, acute heart failure, pulmonary embolism and pulmonary fibrosis need 'high flow oxygen' either as an initial treatment, or to correct hypoxaemia (insufficient oxygen in the blood). ${ }^{18}$ The guidelines suggest patients with an acute exacerbation of COPD require a more cautious approach using lower concentrations of oxygen. However, the guidelines also recognise that these patients are less responsive to supplemental oxygen when compared with non-COPD patients and so may need a higher dose of oxygen than expected. ${ }^{2}$ We should also remember that patients may have other pulmonary conditions co-existing with COPD. The American College of Surgeons recommends $\mathrm{HCO}$ for major trauma victims. ${ }^{19}$ Other authorities have simply advocated giving sufficient supplemental oxygen to achieve the desired degree of oxygenation. ${ }^{2,20}$

There are other (non-COPD) patients who do not require the use of high concentration oxygen or, possibly, any oxygen at all to treat their condition. The key question is whether such patients would be damaged by the short-term use of $\mathrm{HCO}$ in the ambulance. There is no convincing evidence to suggest short-term inhalation of $\mathrm{HCO}$ is detrimental to these patients.

Patients with COPD are not a homogeneous group. Some receiving $\mathrm{HCO}$ will develop hypercapnia but a large proportion will not. ${ }^{2,6,8,9}$ For most COPD patients, significant hypoxia is a more potent and frequent physiological problem than hypercapnia/acidosis. ${ }^{2,11,21-23}$

We have now established that many patients in our target population (patients in an ambulance) will almost certainly benefit from $\mathrm{HCO}$. Some patients with minor illnesses will derive no benefit but also won't experience any detrimental effects. A small proportion (a subset of COPD patients) may suffer harm due to hypercapnia/ acidosis but, in such circumstances, the benefit of noninvasive ventilation on outcome is known. ${ }^{12}$ It should also be remembered that hypoxia, the more frequent threat in terms of morbidity and mortality, has a much more rapid onset of effect than hypercapnia. ${ }^{2}$

If we were to implement a policy of not using $\mathrm{HCO}$ to treat patients with COPD, diagnostic certainty becomes key. There may be lack of objective evidence to support the diagnosis, ${ }^{24}$ for example COPD can also be misdiagnosed as asthma. ${ }^{25}$ In the Austin study, 405 patients were recruited by pre-hospital personnel as fulfilling the criteria for a diagnosis of acute exacerbation of COPD, but only 2/4 met the requirements on hospital review. ${ }^{5}$ In another study only $58 \%$ of patients with COPD were correctly identified in the ambulance. ${ }^{13}$

\section{THE SOLUTION}

Fortunately, there is a way to deliver the benefits of $\mathrm{HCO}$ to the majority of patients while avoiding potential harm in the minority. When prescribing a drug, we normally 
administer what is viewed as an appropriate dose and, if serious harm is possible due to toxicity, we either monitor the patient to detect early signs of known potential harm or if a 'toxic' level has been established, we monitor drug levels. For the drug oxygen, dosage adjustment and prevention of potential 'toxicity' is readily available through the use of pulse oximetry and appropriate targets for oxygen saturation $\left(\mathrm{SpO}_{2}\right)$. In a prospective controlled trial, paramedics used less oxygen on days when they had access to pulse oximetry ${ }^{26}$ and in a cost-benefit analysis of pre-hospital pulse oximetry, $44 \mathrm{I}$ of I,787 patients had their oxygen flow reduced or stopped when guided by $\mathrm{SpO}_{2}$, producing a $26 \%$ reduction in the total amount of oxygen used. ${ }^{27}$

As discussed earlier, a lack of oxygen at cellular level (hypoxia) is a much more common physiological insult than hypercapnia and will cause morbidity and mortality more rapidly. The appropriate strategy would therefore be to address hypoxia first by starting oxygen at a high dose using $\mathrm{HCO}$ and titrating downwards - rather than starting with a low dose and increasing, thus inadvertently prolonging the period of hypoxia. When fractional inspired oxygen (the amount of oxygen that a person is breathing $\left[\mathrm{FiO}_{2}\right]$ ) is reduced, some COPD patients who have developed respiratory depression show spontaneous correction of both hypercapnia and increased hydrogen ion concentration (low potential hydrogen $[\mathrm{pH}]$ levels). ${ }^{2,28}$ It is important that downward titration of $\mathrm{HCO}$ is an active process, occurring quickly and guided by pulse oximetry and other clinical considerations.

\section{OXYGEN THERAPY - MAKING CLINICAL PRACTICE RELIABLE}

Commencing oxygen at a high dose and using pulse oximetry to (i) monitor saturation and (ii) guide downward titration of oxygen dose delivered, corrects life-threatening hypoxia, potentially reduces the period of tissue hypoxia and reduces the risk of elevated arterial oxygen levels (arterial hyperoxia) which may promote hypercapnia in some COPD/asthma patients. This approach also allows an early step in airway management to be the same in all patients - the application of $\mathrm{HCO}$.

Consistent early treatment is particularly important. While overall management of illness is often complex, keeping initial interventions simple and uniform is the ideal. This is a fundamental principle of quality improvement and has driven the development of structured practices to be performed collectively, reliably and consistently (care bundles) which improve the reliability of clinical care..$^{29,30}$ Complex guidelines and protocols increase the likelihood of low compliance, poor reliability and potentially poor care, as indicated in the Austin study. ${ }^{4}$ Austin et al. found that $56 \%$ of the patients in the protocol arm of their clinical trial did not receive the correct treatment. ${ }^{4}$ In another study only $62 \%$ of oxygen-use by ambulance staff was found to fulfil the relevant guidelines. ${ }^{13}$

\section{CONCLUSION}

Keep it simple. All patients should initially receive $\mathrm{HCO}$ in the ambulance. This will help ensure the majority who would benefit, do so. Rapid (downward) titration of the oxygen dose should be performed until either an interim $\mathrm{SpO}_{2}$ target of $92-94 \%$ is reached or the oxygen has been discontinued. At this point the issue of COPD, hypercapnia and hypoxia-dependent respiratory drive can be addressed, particularly if the patient appears more obtunded. Further reduction of the oxygen concentration (dose) in order to achieve a lower $\mathrm{SpO}_{2}$ level can then be considered. The difficulty in identifying such patients will be no more difficult (and may be easier) at this point than before any oxygen was administered.

This approach gives clarity to pre-hospital personnel, avoids hypoxia and excessive hyperoxia and makes pre-hospital oxygen therapy simple, uniform, reproducible and reliable.

\section{REFERENCES}

I Leach RM, Treacher DF. The pulmonary physician in critical care $* 2$ : oxygen delivery and consumption in the critically ill. Thorax 2002; 57: I 70-7. http://dx.doi.org//0.1 I36/thorax.57.2.170

2 Murphy R, Driscoll P, O'Driscoll R. Emergency oxygen therapy for the COPD patient. Emerg Med J 200I; 18:333-9. http://dx.doi. org/10.II36/emj.18.5.333

3 Sassoon CSH, Hassell KT, Mahutte CK. Hyperoxic-induced hypercapnia in stable chronic obstructive pulmonary disease. Am Rev Respir Dis 1987; I35:907-II.

4 Sieker HO, Hickam JB. Carbon dioxide intoxication: the clinical syndrome, its aetiology and management with particular reference to the use of mechanical respirators. Medicine (Baltimore) 1956; 35:389-423.

5 Austin MA,Wills KE, Blizzard L et al. Effect of high flow oxygen on mortality in chronic obstructive pulmonary disease patients in prehospital setting: randomised controlled trial. BMJ 2010; 341:c5462. http://dx.doi.org/10.1 I36/bmj.c5462

6 Westlake EK, Simpson T, Kaye M. Carbon dioxide narcosis in emphysema. QJ Med 1955; 24:155-73.

7 Aubier M,Murciano D, Milic-Emili J et al.Effects of the administration of $\mathrm{O} 2$ on ventilation and blood gases in patients with chronic obstructive pulmonary disease during acute respiratory failure. Am Rev Respir Dis 1980; 122:747-54.

8 Robinson TD, Freiberg DB, Regnis JA et al.The role of hypoventilation and ventilation-perfusion redistribution in oxygen-induced hypercapnia during acute exacerbations of chronic obstructive pulmonary disease. Am J Respir Crit Care Med 2000; I61:1524-9.

9 Crossley DJ, McGuire GP, Barrow PM et al. Influence of inspired oxygen concentration on deadspace, respiratory drive, and $\mathrm{PaCO} 2$ in intubated patients with chronic obstructive pulmonary disease. Crit Care Med 1997; 25:I522-6. http://dx.doi.org/I0.1097/00003246-199709000-00019

10 Denniston AK, O'Brien C, Stableforth D. The use of oxygen in acute exacerbations of chronic obstructive pulmonary disease: a prospective audit of pre-hospital and hospital emergency management. Clin Med 2002; 2:449-51. 
II Durrington HJ, Flubacher M, Ramsay CF et al. Initial oxygen management in patients with an exacerbation of chronic obstructive pulmonary disease. QJM 2005; 98:499-504. http://dx. doi.org/I0.1093/qjmed/hci084

12 Plant PK, Owen JL, Elliott MW. Early use of non-invasive ventilation for acute exacerbations of chronic obstructive pulmonary disease on general respiratory wards: a multicentre randomised controlled trial. Lancet 2000; 355:193I-5. http://dx.doi.org/I0.10I6/S0I406736(00)02323-0

I 3 Hale KE, Gavin C, O'Driscoll BR.Audit of oxygen use in emergency ambulances and in a hospital emergency department. Emerg Med J 2008; 25:773-6. http://dx.doi.org/I0.I I36/emj.2008.059287

14 Beasley R, Aldington S, Robinson G. Is it time to change the approach to oxygen therapy in the breathless patient? Thorax 2007; 62:840-I. http://dx.doi.org/I0.I I36/thx.2006.068866

I5 Balan IS, Fiskum G, Hazelton J et al. Oximetry-guided reoxygenation improves neurological outcome after experimental cardiac arrest. Stroke 2006; 37:3008-13. http://dx.doi.org/l0.II6I/0I. STR.0000248455.73785.b I

I6 Kilgannon JH, Jones AE, Shapiro NI et al.Association between arterial hyperoxia following resuscitation from cardiac arrest and in-hospital mortality. JAMA 20I0; 303:2165-7I. http://dx.doi.org/l0.100I/ jama.2010.707

17 Bitterman H. Bench-to-bedside review: oxygen as a drug. Crit Care 2009; 13:205. http://dx.doi.org/|0.II86/cc7|5|

I8 O'Driscoll BR, Howard LS, Davison AG. BTS guideline for emergency oxygen use in adult patients. Thorax 2008; 63:vil-68. http://dx.doi.org// 0.1 I36/thx.2008.102947

19 American College of Surgeons. Advance Trauma Life Support provider manual [Internet]. Chicago: American College of Surgeons; 1997. Available at: https://web4.facs.org/ebusiness/ProductCatalog/product. aspx?ID=230

20 Nolan JP, Hazinski MF, Billi JE et al. Part I: Executive summary: 2010 international consensus on cardiopulmonary resuscitation and emergency cardiovascular care science with treatment recommendations. Resuscitation 2010; 81:el-e25. http://dx.doi. org/10.1016/j.resuscitation.2010.08.002
21 Garrod R, Paul EA, Wedzicha JA. Supplemental oxygen during pulmonary rehabilitation in patients with COPD with exercise hypoxaemia. Thorax 2000; 55:539-43. http://dx.doi.org//0./136/ thorax.55.7.539

22 Calverley PM. Supplementary oxygen therapy in COPD: is it really useful? Thorax 2000; 55:537-8. http://dx.doi.org/I0.I I36/thorax.55.7.537

23 Bateman NT, Leach RM. ABC of oxygen. Acute oxygen therapy. BMJ 1998; 317:798-80I.

24 Butler MW, O'Mahony MJ, Donnelly SC et al. Managing exacerbations of COPD: room for improvement. Ir Med J 2004; 97:108-10.

25 Stow PJ, Pilcher D, Wilson J et al. Improved outcomes from acute severe asthma in Australian intensive care units (1996-2003). Thorax 2007; 62:842-7. http://dx.doi.org/I0.1 I36/thx.2006.0753I7

26 Howes DW, Field B, Leary $T$ et al. Justification of pulse oximeter costs for paramedic prehospital providers. Prehosp Emerg Care 2000; 4: I5I-5. http://dx.doi.org//0.1080/10903/2009094/425

27 Macnab AJ, Susak L, Gagnon FA et al. The cost-benefit of pulseoximeter use in the prehospital environment. Prehosp Disaster Med 1999; 14:245-50.

28 Plant PK, Owen JL, Elliott MW. One year period prevalence study of respiratory acidosis in acute exacerbations of COPD: implications for the provision of non-invasive ventilation and oxygen administration. Thorax 2000; 55:550-4. http://dx.doi.org/I0.I I36/thorax.55.7.550

29 Institute for Healthcare Improvement. Raising the bar with bundles: treating patients with an all-or-nothing standard [Internet]. Massachusetts:Institute for Healthcare Improvement; 2006 [cited 201 I Sept 5]. Available from: http://www.ihi.org/knowledge/Pages/ Publications/RaisingtheBarwithBundles.aspx

30 Resar R, Pronovost P, Haraden C et al. Using a bundle approach to improve ventilator care processes and reduce ventilator-associated pneumonia. Jt Comm J Qual Patient Saf 2005; 31:243-8.

\title{
High concentration oxygen should not be given to all patients treated in an ambulance
}

\author{
PA Corris
}

\section{BACKGROUND PHYSIOLOGY}

Oxygen was discovered by both CarlWilhelm Scheele in Uppsala in 1773 and Joseph Priestley in Wiltshire in 1774, working independently, but Priestley is generally given credit because his work was published first.' The term 'oxygen' was first used by Antoine Lavoisier in 1777, whose experiments 'helped to discredit the thenpopular phlogiston theory of combustion and corrosion'.' Oxygen is of course vital for all mammalian cells to survive. Transfer into the body takes place in the alveoli of the lung, and it is transported via the circulatory system, bound to haemoglobin in red blood cells. Oxygen comprises $20.95 \%$ of the Earth's atmospheric gas, and though vital to life, to paraphrase Shakespeare, 'too much of a good thing can produce harm'. The definition of a poison includes a 'substance that causes injury, illness or death' and high levels of inspired concentrations of oxygen fulfil all these criteria.
Breathing elevated concentrations of oxygen can lead to hyperoxaemia, with the development of supraphysiological levels of oxygen in body tissues. The body may be affected in different ways depending on the type of hyperoxaemic exposure. Central nervous system toxicity typically occurs following short exposure to high concentrations of oxygen $(\mathrm{HCO})$ at greater than atmospheric pressure. Pulmonary and ocular toxicity result from longer exposure to elevated oxygen levels at normal pressure. Symptoms include disorientation, breathlessness due to lung injury, and abnormalities of vision such as myopia. Prolonged or very high oxygen concentrations can cause oxidative damage to cell membranes, the collapse of the alveoli in the lungs leading to atelectasis and/or retinal detachment and seizures. ${ }^{2}$ Oxygen toxicity is managed by reducing the exposure to elevated oxygen concentrations and, usually, recovery occurs in the long-term. 
Protocols exist to avoid hyperoxaemia ${ }^{2}$ in areas where oxygen is breathed at higher than normal partial pressures, such as underwater diving using compressed breathing gases, hyperbaric medicine, neonatal care and human spaceflights. These protocols have resulted in a decreased incidence of seizures caused by oxygen toxicity, and pulmonary and ocular damage is now predominantly confined to the management of the care of premature infants.

In an acute medical setting, high flow HCO therapy is commonly given to patients on their way to hospital in the ambulance, due to a belief that there are benefits. There is increasing evidence however that many patients who receive HCO may be harmed by this approach.

\section{CARDIOVASCULAR AND CEREBROVASCULAR DISEASE}

Thomson et al. summarised the theoretical risks of hyperoxaemia in vascular diseases of both the heart and central nervous system in an editorial which made a strong case for more trials. ${ }^{3}$ Hyperoxaemia may result in coronary vasoconstriction. One randomised double blind trial of the use of oxygen in cases of uncomplicated myocardial infarction found higher rates of sinus tachycardia and a significantly greater rise in cardiac enzymes in the group receiving oxygen, in keeping with a greater infarct size. ${ }^{4}$ There was a threefold increase in mortality in patients on oxygen therapy but it did not reach statistical significance (three deaths in 77 patients treated with air versus nine deaths in 80 patients given oxygen at 6 litres per minute [l/ $\mathrm{min}$ ] through a simple face mask for 24 hours). This trial was published in 1976 and oxygen has since been given routinely to millions of normoxaemic patients with myocardial infarction and chest pain for over 30 years without any evidence to support the practice.

Furthermore, a more recent trial showed increased mortality in normoxaemic patients who had strokes of mild to moderate severity in those randomised to receive treatment with oxygen. This result supports the urgent need for large randomised trials of oxygen therapy for nonhypoxaemic patients with acute cardiac and cerebral ischaemia. Thompson et al. ${ }^{3}$ have suggested that oxygen should be 'prescribed, administered and monitored with care' in order 'to achieve optimal tissue oxygenation', not maximal oxygenation. This view was proposed by other authors such as Bryan and Jenkinson ${ }^{5}$ in the 1980s, but standard medical practice has not taken note of this advice. Because there are no published data suggesting that most medical conditions benefit from hyperoxaemia, and because of the theoretical risks the best evidence-based management should aim for physiological oxygenation.

Aside from the potentially detrimental physiological effects of hyperoxaemia, the toxic effects mediated by reactive oxygen species (ROS) also have potential risks.
Excess ROS, in the form of hydrogen peroxide and superoxide, are generated in the presence of high tissue partial pressures of oxygen $\left(\mathrm{PO}_{2}\right)$, causing oxidative stress and free radical damage. At physiological levels, ROS act as signalling molecules, but at higher levels they are cytotoxic, notably when released by primed neutrophils as a host defence mechanism. ${ }^{6}$ It is thought that ROS are responsible for the development of bronchopulmonary dysplasia in hyperoxygenated ventilated premature infants and for reperfusion injury (post-myocardial infarction and embolic stroke for example).

\section{CHRONIC RESPIRATORY DISEASE}

Although it is important to consider adverse effects of oxygen therapy in cardiovascular and cerebrovascular disease, nowhere is the poisonous property of oxygen therapy administered in the ambulance better demonstrated than when treating exacerbations of chronic obstructive pulmonary disease (COPD). This is a major public health problem in many countries; the World Health Organization for example estimates that 210 million people have moderate to severe COPD and that three million people died of the condition in 2005. .-10 $^{-10}$ The costs to healthcare systems worldwide are high. ${ }^{.1-13}$ The course of the disease is characterised by acute exacerbations, typified by the worsening of three key symptoms, including cough, sputum production and breathlessness. Such exacerbations are a frequent cause of admission to hospital by ambulance. Standard prehospital management 'includes nebulised bronchodilators (usually driven by $6-8 \mathrm{l} / \mathrm{min}$ of oxygen), corticosteroids, and oxygen,.,10,13,14

High concentrations of administered oxygen to acutely hypoxic patients can save lives by improving severe hypoxaemia. In treating acute non-hypercapnic respiratory failure however, the administration of high flow oxygen to patients without COPD leads to an increase in minute ventilation and a decrease in end tidal carbon dioxide concentration. ${ }^{14}$ In susceptible hypoxic patients with stable COPD, hyperoxia leads to a decrease in minute ventilation and an increase in carbon dioxide. ${ }^{14,17,18}$ These changes result from both the depression of ventilation and the worsening inequality in the ventilation/perfusion mismatch due to the use of poorly ventilated regions of the lungs. ${ }^{19}$

In 1949, Donald ${ }^{20}$ recognised that a proportion of patients with chronic respiratory disease had a tendency to become hypercapnic on high inspired concentrations of oxygen $\left(\mathrm{FiO}_{2}\right)$. This was confirmed by $\mathrm{McNicol}$ and Campbell's 1965 study of arterial blood gases (ABGs) in respiratory failure. ${ }^{21,22}$ More than three decades later, in a large, prospective, prevalence study of COPD admissions, Plant et al. ${ }^{23}$ showed a strong positive correlation between the severity of respiratory acidosis and the arterial oxygen tension $\left(\mathrm{PaO}_{2}\right)$. In most hypercapnic patients, a $\mathrm{PaO}_{2}$ of $>10$ 
kilopascals $(\mathrm{kPa})$ was associated with both acidosis and administration of high concentrations of inspired oxygen. Hypercapnia induced in this way can cause severe lifethreatening narcosis. ${ }^{24,26}$ If high $\mathrm{FiO}_{2}$ concentrations are delivered routinely to all patients in ambulances, it is inevitable that a proportion will develop this potentially serious condition. Recent studies indicate that this is a relatively common occurrence in pre-hospital and accident and emergency settings. ${ }^{26-28}$ It is also important however to limit the risk of inadequate resuscitation of hypoxic patients who are not at risk of hypercapnia.

Recent studies have shown that the administration of high flow oxygen during acute exacerbations of COPD are associated with increases in mortality, length of hospital stay, requirement for ventilation, and admission to high dependency units. ${ }^{10,28,29}$ The use of titrated oxygen treatment has been associated with less acidosis, a lower requirement for assisted ventilation and reduced mortality. ${ }^{1,29-33}$

The Department of Respiratory Medicine at Southend Hospital and the Essex Ambulance Service devised an 'alert card' system to identify individuals known to be at particular risk of retaining carbon dioxide while receiving high $\mathrm{FiO}_{2 .}{ }^{23}$ The scheme has been audited and its effectiveness demonstrated; the strategy is now incorporated into the British Thoracic Society (BTS) emergency oxygen guidelines. They also contributed to the success of the BTS, Salford Royal NHS Foundation Trust and Southend University Hospital NHS Foundation Trust winning a National Patient Safety Award in 201 I (www.brit-thoracic.org.uk).

The benefits of monitoring the concentration of oxygen delivered in the ambulance setting, rather than routinely delivering a high $\mathrm{FiO}_{2}$ to patients with COPD exacerbations, have recently been demonstrated in an Australian study. ${ }^{10}$ This was motivated by the need for quantitative evidence to support recommendations for the use of controlled titrated oxygen treatment for patients with an acute exacerbation of COPD. The study compared standard high flow oxygen treatment with titrated oxygen therapy, in the pre-hospital management of patients with an acute exacerbation of COPD.

A significant difference in mortality of patients thought to have COPD was observed between the two treatment arms (relative risk 0.42 for titrated oxygen, 95\% confidence interval 0.20 to $0.89 ; p=0.02$ ). Mortality was $9 \%$ (2l deaths) in the high flow oxygen arm compared with $4 \%$ (seven deaths) in the titrated oxygen arm. In the subgroup with confirmed COPD, there was also a significant difference in mortality: $9 \%$ (II deaths) in the high flow arm compared with $2 \%$ (two deaths) in the titrated oxygen arm (relative risk $0.22,0.05$ to 0.91 ; $p=0.04$ ). All deaths occurred after the patient had arrived in hospital, including two in the emergency department and two in the intensive care unit. Hypercapnic respiratory failure was the primary cause of death in all cases, and approximately $70 \%$ of deaths in both treatment arms occurred within the first five days of admission. ${ }^{10}$

Many patients, including a proportion of those with chronic respiratory disease, will not develop serious hypercapnic acidosis due to administration of high concentrations of oxygen but some will. Therefore, recognising the dangers of blunderbuss oxygen therapy, the National Institute of Health and Clinical Excellence has recently recommended the use of controlled titrated oxygen delivery in the management of acute exacerbations of COPD, with supplemental oxygen titrated to maintain oxygen saturations at $90-93 \%{ }^{34}$ The BTS have also accepted the poisonous qualities of oxygen and have made similar recommendations, but with a target oxygen saturation level of $88-92 \%{ }^{35}$

The delivery of $\mathrm{HCO}$ to all hypoxic patients during transfer to hospital, or indeed, to many non-hypoxic patients suffering a stroke or myocardial infarction, will be poisonous to many, and this practice must be stopped immediately. If we are to prevent premature mortality, implementing procedures for preventing oxygen-induced hypercapnoea (and as a consequence, respiratory acidosis) in patients with exacerbations of COPD requires the vertical integration of care from the ambulance service to the emergency room. Evidence to support this view has been available since 1949. Is it not timely that we now practice evidence-based medicine for all such patients?

\section{REFERENCES}

I Austin MA, Willis KE, Blizzard L et al. Effect of high flow oxygen on mortality in chronic obstructive pulmonary disease patients in pre hospital setting: randomised controlled trial. BMJ 2010; 34I:c5462. http://dx.doi.org/I0.II36/bmj.c5462

2 Donald K. Oxygen poisoning in man. Br Med J 1947; I:667. http:// dx.doi.org/ I0.1 I36/bmj. I.4506.667

3 Thomson AJ,Webb DJ, Maxwell SR et al. Oxygen therapy in acute medical care. BMJ 2002; 324:|406-7. http://dx.doi.org//0.1/36/ bmj.324.735I.I406

4 Rawles JM, Kenmure AC. Controlled trial of oxygen in uncomplicated myocardial infarction. Br Med J 1976; I:II2I-3. http://dx.doi.org/I0.1136/bmj.I.6018.1121

5 Bryan CL, Jenkinson SG. Oxygen toxicity. Clin Chest Med 1988; I:|4|-52.

6 Auten RL, Davis JM. Oxygen toxicity and reactive oxygen species: the devil is in the details. Pediatr Res 2009; 66:121-7. http://dx.doi. org/I0.I203/PDR.0b0I3e3I8Ia9eafb

7 World Health Organization [Internet]. Chronic obstructive pulmonary disease (COPD) [cited 201 I $19 \mathrm{Oct}$ ]. Available from: www.who.int/respiratory/copd/en/

8 American LungAssociation. State of lung disease in diverse communities 2010 [Internet]. Washington DC:American Lung Association; 2010 [cited 2011 $190 \mathrm{Oct}$ ]. Available from: www.lungusa.org/assets/ documents/publications/solddc-chapters/copd.pdf.

9 British Lung Foundation. Invisible lives: chronic obstructive pulmonary disease (COPD) - finding the missing millions [Internet]. London: British Lung Foundation; 2007 [cited $201 \mathrm{I} 19 \mathrm{Oct}$ ]. Available from: www. lunguk.org/Resources/British\%20Lung\%20Foundation/Migrated\%20 Resources/Documents///Invisible\%20Lives\%20report.pdf 
10 Gooptu B, Ward L, Ansari SO et al. Oxygen alert cards and controlled oxygen: preventing emergency admissions at risk of hypercapnic acidosis receiving high inspired oxygen concentrations in ambulances and A\&E departments. Emerg Med J 2006; 23:636-8. http://dx.doi.org/I0.I I36/emj.2005.02999 I

II Halpern MT, Stanford RH, Borker R. The burden of COPD in the USA: results from the confronting COPD survey. Respir Med 2003; 97:S8I-9. http://dx.doi.org/I0.1016/S0954-6 I I I(03)80028-8

12 McKenzie DK, Frith PA, Burdon JG et al. The COPDX plan: Australian and New Zealand guidelines for the management of chronic obstructive pulmonary disease. Med J Aust 2003; I78:S7-39.

I3 Mittmann N, Kuramoto L, Seung SJ et al. The cost of moderate and severe COPD exacerbations to the Canadian healthcare system. Respir Med 2008; I02:4I3-2I. http://dx.doi.org/I0.1016/j. rmed.2007.10.010

I4 Hale KE, Gavin C, O'Driscoll BR. Audit of oxygen use in emergency ambulances and in a hospital emergency department. Emerg Med J 2008; 25:773-6. http://dx.doi.org/I0.II36/ emj.2008.059287

I5 O'Driscoll BR, Howard LS, Davison AG. BTS guideline for emergency oxygen use in adult patients. Thorax 2008; 63:vil-68. http://dx.doi.org/I0.I I36/thx.2008.102947

16 Becker HF, Polo O, McNamara SG et al. Effect of different levels of hyperoxia on breathing in healthy subjects. J Appl Physiol 1996; 81:1683-90.

17 Sassoon CS, Hassell KT, Mahutte CK. Hyperoxic-induced hypercapnia in stable chronic obstructive pulmonary disease. Am Rev Respir Dis 1987; |35:907-1।.

18 Westlake EK, Simpson T, Kaye M. Carbon dioxide narcosis in emphysema. Q J Med 1955; 24:I55-73.

19 Soler-Cataluna JJ, Martinez-Garcia MA, Sanchez PR et al. Severe acute exacerbations and mortality in patients with chronic obstructive pulmonary disease. Thorax 2005; 60:925-31. http:// dx.doi.org/ I0.1 I36/thx.2005.040527

20 Donald K. Neurological effects of oxygen. Lancet 1949; 257:1056-7. http://dx.doi.org/I0.10I6/S0I40-6736(49)9I632-3

21 McNicol MW, Campbell EJ. Severity of respiratory failure. Arterial blood-gases in untreated patients. Lancet 1965; 1:336-8. http:// dx.doi.org/I0.1016/S0140-6736(65)91774-5

22 Campbell E. The J Burns Amberson lecture: the management of acute respiratory failure in chronic bronchitis and emphysema. Am Rev Respir Dis 1967; 96:626-39.

23 Plant PK, Owen JL, Elliott MW. One year period prevalence study of respiratory acidosis in acute exacerbations of COPD: implications for the provision of non-invasive ventilation and oxygen administration. Thorax 2000; 55:550-4. http://dx.doi.org// 0.I I36/thorax.55.7.550
24 Jeffrey AA, Warren PM, Flenley DC.Acute hypercapnic respiratory failure in patients with chronic obstructive lung disease: riskfactors and use of guidelines for management. Thorax 1992; 47:34-40. http://dx.doi.org//0.1 I36/thx.47.I.34

25 Denniston A, O'Brien C, Stableforth D. The use of oxygen in acute exacerbations of chronic obstructive pulmonary disease: a prospective audit of pre-hospital and hospital emergency management. Clin Med 2002; 2:449-5I.

26 Joosten EA.The effects of oxygen therapy in patients presenting to an emergency department with exacerbation of chronic obstructive pulmonary disease. Med J Aust 2007; 5:235-8.

27 Robinson TD, Freiberg DB, Regnis JA et al. The role of hypoventilation and ventilation-perfusion redistribution in oxygeninduced hypercapnia during acute exacerbations of chronic obstructive pulmonary disease. Am J Respir Crit Care Med 2000; 161:1524-9.

28 Wijesinghe M, Perrin K, Healy B et al. Pre-hospital oxygen therapy in acute exacerbations of chronic obstructive pulmonary disease. Intern Med J 20 I I; 4 I:6 I8-22. http://dx.doi.org/ I 0. I I I I/ i. 1445-5994.2010.02207.x

29 Austin M, Wood-Baker R. Oxygen therapy in the pre-hospital setting for acute exacerbations of chronic obstructive pulmonary disease. Cochrane Database Syst Rev 2006; 3:CD005534.

30 Price LC, Lowe D, Hosker HS et al. UK National COPD Audit 2003: impact of hospital resources and organisation of care on patient outcome following admission for acute COPD exacerbation. Thorax 2006; 61:837-42. http://dx.doi.org/I0.1 I 36/thx.2005.049940

$3 \mathrm{I}$ Eiser DN. Comparison of controlled oxygen with standard oxygen therapy for COPD patients during ambulance transfer to hospital. London: London Ambulance Service NHS Trust; 2004.

32 Plant PK, Owen JL, Elliott MW. Non-invasive ventilation in acute exacerbations of chronic obstructive pulmonary disease: long term survival and predictors of in-hospital outcome. Thorax 200I; 56:708-12. http://dx.doi.org/10.1 I36/thorax.56.9.708

33 New A. Oxygen: kill or cure? Pre-hospital hyperoxia in the COPD patient. Emerg Med J 2006; 23:|44-6. http://dx.doi.org/I0.II36/ emj.2005.027458

34 National Institute of Health and Clinical Excellence (NICE). CGI2 Chronic obstructive pulmonary disease: NICE Guideline [Internet]. NICE: 2004 [cited 20I I Oct]. Available from: http://guidance.nice. org.uk/CGI2

35 British Thoracic Society. Emergency oxygen use in adult patients [Internet]. London: BTS; 2008 [cited 20II Oct]. Available from: http://www.brit-thoracic.org.uk/guidelines/emergency-oxygenuse-in-adult-patients 